Review

\title{
Less Is More: The Physiological Basis for Tapering in Endurance, Strength, and Power Athletes
}

\section{Kevin A. Murach ${ }^{1,2, *}$ and James R. Bagley ${ }^{2}$}

1 Department of Rehabilitation Sciences, College of Health Sciences and Center for Muscle Biology, University of Kentucky, MS-508 Chandler Medical Center, 800 Rose Street, Lexington, KY 40508, USA

2 Department of Kinesiology, College of Health and Social Sciences, San Francisco State University, 1600 Holloway Avenue-Gym 101, San Francisco, CA 94132, USA; E-Mail: jrbagley@sfsu.edu

* Author to whom correspondence should be addressed; E-Mail: kmu236@g.uky.edu; Tel.: +1-859-257-2375.

Academic Editor: Lee E. Brown

Received: 10 July 2015 / Accepted: 17 August 2015 / Published: 21 August 2015

\begin{abstract}
Taper, or reduced-volume training, improves competition performance across a broad spectrum of exercise modes and populations. This article aims to highlight the physiological mechanisms, namely in skeletal muscle, by which taper improves performance and provide a practical literature-based rationale for implementing taper in varied athletic disciplines. Special attention will be paid to strength- and power-oriented athletes as taper is under-studied and often overlooked in these populations. Tapering can best be summarized by the adage "less is more" because maintained intensity and reduced volume prior to competition yields significant performance benefits.
\end{abstract}

Keywords: taper; reduced-volume training; periodization; skeletal muscle; fiber type

\section{Introduction}

Taper can be defined as a structured reduction in training volume (as compared to peak training load) for a specific period of time prior to athletic competition as a means to enhance performance. In simpler terms, taper is formalized recovery training that occurs after a heavy training block. Rest as an integral aspect of training is not a recent concept. The importance of obligatory recovery time during training was recognized as early as the ancient Olympic games [1]. However, the role of adequate rest in 
optimizing performance has been more widely publicized in the last 60 years with the concept of periodization [2,3], or varied training (i.e., mode, time, intensity) for a specific goal.

Endurance athletes have systematically practiced relative rest via reduced-volume training as a means to improve performance for at least 50 years. However, Costill and colleagues [4] in 1985 were the first to experimentally evaluate the physiological effects of a specific tapering protocol using competitive swimmers. Since that time, taper's efficacy has been well documented in swimming, cycling, running, triathlon, rowing, strength training, and team sports to name a few. The effects of tapering are apparent from the whole body (macro) [4] to the cell and gene (micro) [5,6] levels and even include psychological improvements [7]. Despite the multitude of data supporting taper's effectiveness, some athletes and coaches still fail to acknowledge its importance and implement the practice. The purpose of this article is to highlight how taper is experimentally shown to enhance athletic performance across multiple exercise modes and populations. An overview of tapering in endurance-type athletes will be provided, but special attention will be paid to strength- and power-oriented athletes for whom tapering is generally less emphasized. Additionally, the discussion will highlight taper-mediated skeletal muscle improvements and provide broad literature-based guidance for tapering. We hope to underscore the necessity for coaches and athletes to employ well-controlled taper regimens during their training programs.

\section{How to Taper}

An effective taper regimen can be conducted in numerous ways. The duration and type of taper generally varies by sport but the common theme among endurance tapering protocols is a substantial reduction in training volume prior to competition. The literature suggests that an effective taper could be as short as four days [8] and involve reductions in training volume of up to $90 \%$ [9,10]. An improperly conducted taper where endurance exercise volume is only reduced by $25 \%$ and high- intensity work is increased to compensate will not yield favorable results [11]. Increasing training volume instead of tapering affords no benefits and may hinder performance $[12,13]$. For most endurance-oriented activities, a taper lasting two to three weeks characterized by a $40 \%-70 \%$ reduction in volume from peak training with maintained intensity will produce significant performance benefits. For a more in-depth review of specific endurance tapering protocols, refer to Mujika et al. [14], Bosquet et al. [15], and Wilson et al. [16].

The nature of taper is less defined in the literature regarding intermittent type athletic disciplines such as strength-focused weightlifting, power-focused Olympic-style weightlifting, and track and field or team sports where both strength and power are emphasized. However, a recent review on tapering in strength sports suggests (similar to endurance athletics) that performance is improved with a $30 \%-70 \%$ reduction in volume (via reduced intra-session volume or less overall training frequency) for up to four weeks with maintained or slightly increased intensity [17]. The tapering literature specific to power athletes is particularly limited. However, a recent investigation found a $25 \%-40 \%$ reduction in resistance training volume (sessions per week) with maintained intensity improved throwing performance after two weeks in track and field athletes [18]. Another study found enhanced maximal power output with a three week taper characterized by a $\sim 75 \%$ resistance-training volume reduction, a slight increase in intensity, and maintained sport-specific training in elite rugby players [19]. Similar to endurance athletes, reduced volume with maintained or slightly increased intensity appears to be the key elements for tapering in strength- and power-focused athletes. 


\section{Magnitude of Performance Benefits with Taper}

A properly conducted taper improves race performance across a broad spectrum of athletic activities and populations (Figure 1). It enhances performance in shorter race events (i.e., 50 meter swim, $<10 \mathrm{~km}$ cycling time trial [TT], $2000 \mathrm{~m}$ row) [4,7,13,20-22] as well as middle distance swimming, biking, and running competition [4,5,9,13,20,22-24]. Taper also improves performance indices in longer-duration events such as the duathlon [25], $40 \mathrm{~km}$ cycling TT [26], and triathlon [27,28]. For any distance event, it is reasonable to expect that taper will increase performance on the order of $2 \%-3 \%$. This is no small change when considering that a 3\% improvement in a collegiate 8 kilometer runner's performance could account for a $50 \mathrm{~s}$ faster race time [5]. Moreover, meaningful performance benefits are not exclusive to endurance and race events with tapering. A $2 \%-3 \%$ improvement in the bench press and squat in strength athletes [29] and a 5\%-6\% increase in throwing distance can occur in competitive track and field athletes following a taper period [18].

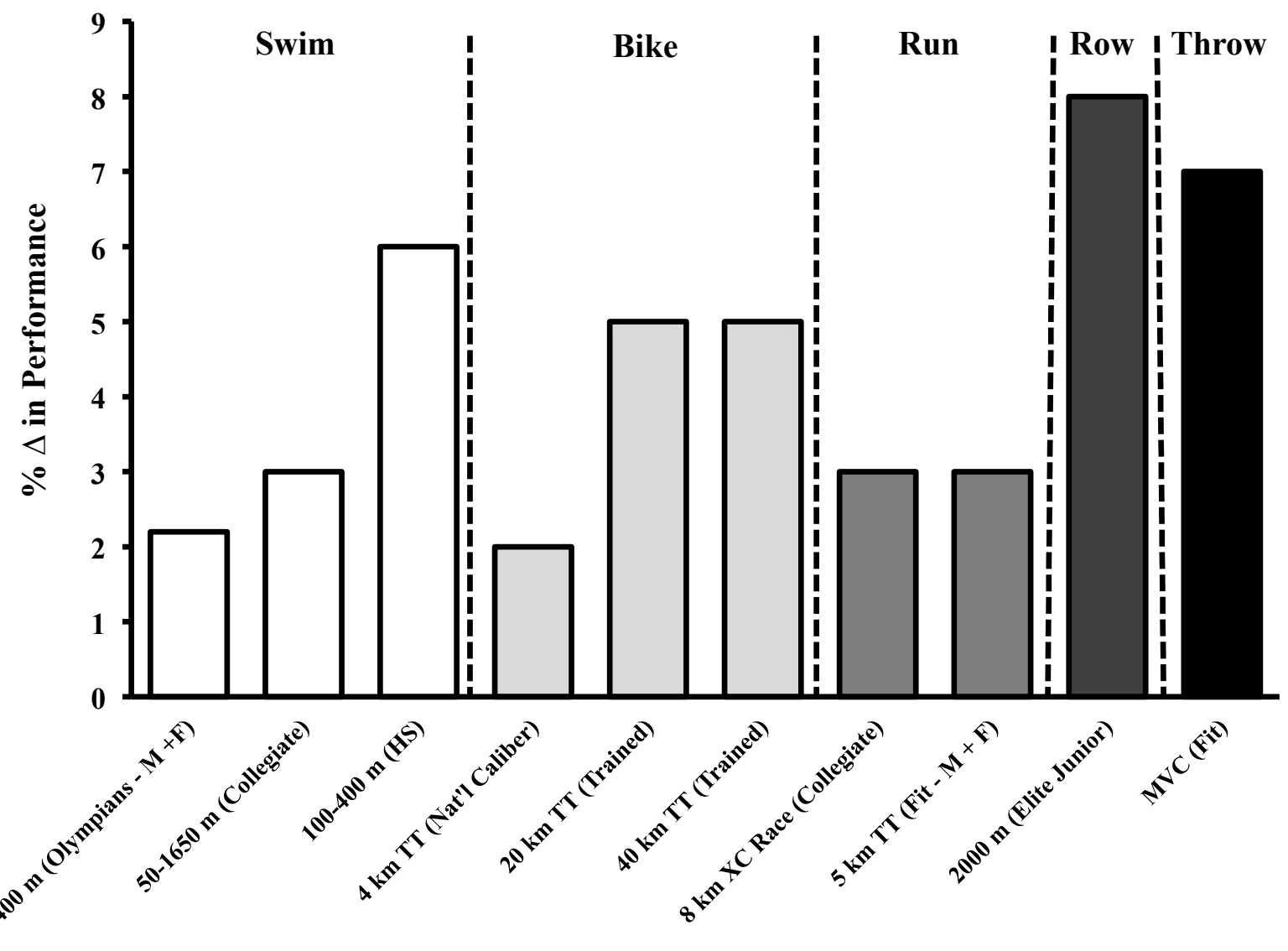

Figure 1. Reported performance benefits from taper in different athletic events and populations. Data were derived from the following studies in order from left to right: Swim-Mujika et al. 2002 [30], Costill et al. 1985 [4], D’Acquisto et al. 1992 [9]. Bike-Berger et al. 1999 [7], Neary et al. 2003 [24], Neary et al. 2003 [26]. Run-Luden et al. 2010 [5], Houmard et al. 1994 [23]. Row-Steinacker et al. 2000 [21]. Throw-Zaras et al. 2014 [18]. $\mathrm{m}=$ Meter; $\mathrm{M}=$ Male; $\mathrm{F}=$ Female; $\mathrm{HS}=$ High School; $\mathrm{TT}=$ Time Trial; $\mathrm{T}+\mathrm{F}=$ Track and Field. 


\section{Fitness Is Not Lost with Taper}

A common misconception among athletes and coaches is that less training always equates to a loss of fitness. However, the literature indicates that fitness in endurance athletes (measured as aerobic capacity, or $\mathrm{VO}_{2 \max }$ ) is not lost following the taper period and five studies have actually shown an increase in fitness with less training [18,21-23,25]. Reducing training volume for as long as four weeks [7] by $>85 \%$ (in the last week) [6,19] still yields gains in performance without a loss of fitness. Considering the robust adaptations observed with short-duration high-intensity interval training, even in already highly trained individuals [26,27], it should come as no surprise that a well-designed taper of reduced volume and quality high intensity work can preserve fitness for up to a month. In strength athletes, short-term complete rest ( $\leq 1$ week) does not reduce force-producing capacity while tapering only seems to improve strength [17]. To our knowledge, there is little to no evidence in the literature showing that a properly conducted taper does not improve fitness indices in endurance, strength, power, or team sport athletes.

\section{Taper and Muscle Energy Usage}

If an athlete consistently trains rigorously and with high volumes, one could expect muscle energy stores (i.e., carbohydrate, or glycogen) to be chronically lowered. Logically, a reduction in training volume during taper with proper diet reverses this condition (Figure 2) [10,24]. Initial muscle glycogen levels do not seem to affect short-term high-intensity performance (i.e., a sprint) [31,32]. Indeed, the performance decrements from overtraining [33] and the performance benefits from taper [26] can occur independent of muscle glycogen levels during shorter duration activities. However, initial glycogen levels do affect performance during repeated high-intensity efforts [34,35] as well as endurance efforts lasting $~ 60$ min or more [36,37]. Expanded muscle glycogen stores may therefore be a desirable taper-induced adaptation for endurance athletes, team sport athletes, and during activities requiring multiple individual efforts in quick succession. Other measures related to muscle energy usage such as lactate $[4,9,10,13,23,38,39]$ and aerobic enzymes $[8,10,26]$ are less affected by tapering. Taper-mediated muscle glycogen replenishment enhances performance in some circumstances but does not fully account for the beneficial effects of tapering.

No Taper

Taper

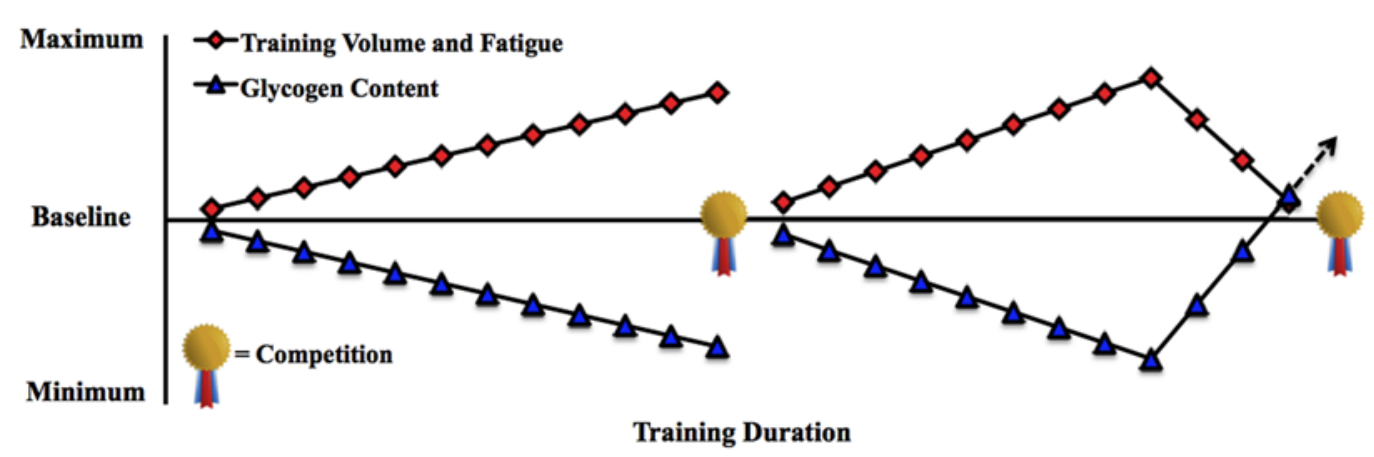

Figure 2. Illustration of training volume, accumulated fatigue, and skeletal muscle glycogen content in response to training with and without taper (assuming proper diet). Concept derived from Sherman et al. [37] and Halson et al. [40]. 


\section{Taper Improves Muscle Power in Endurance Athletes}

Numerous studies spanning various exercise modes and subject populations [21,41-43] have since corroborated the original findings [4] of increased muscle power with taper in endurance athletes (Figure 3). Taper-derived muscle power gains may occur in two phases (early and late) which reinforces that a taper should be of adequate length (generally $\geq 2$ weeks) [43]. One might predict the main effect of tapering in endurance athlete's muscle would be targeted to the highly aerobic slow-twitch muscle fibers. However, it is the less abundant and 5-8 times more powerful fast-twitch fibers that drastically respond $[5,22,26,28]$. These fibers grow at an alarmingly fast rate with taper [5,22,26], improving power output without a measurable change in body mass [5,22]. Improved fast-twitch fiber function may allow for a harder "push" to the finish line or improve economy (faster speed with the same amount of effort). It has recently been shown that favorable regulation of molecular hypertrophy markers, specifically in fast-twitch fibers, may support the high rate of growth in these fibers with tapering [6]. Although taper has a positive effect down to the molecular level, taper-mediated growth is only realized when volume is adequately reduced [11]. To our knowledge, data on the mechanisms of performance enhancement with tapering in strength or power athletes are not available at the muscle cell level. However, strength and power training can selectively hypertrophy fast-twitch muscle fibers [6], potentially maximizing growth adaptation before tapering ensues. Thus, tapering likely augments performance in intermittent-type athletes by a different mechanism than in endurance athletes.

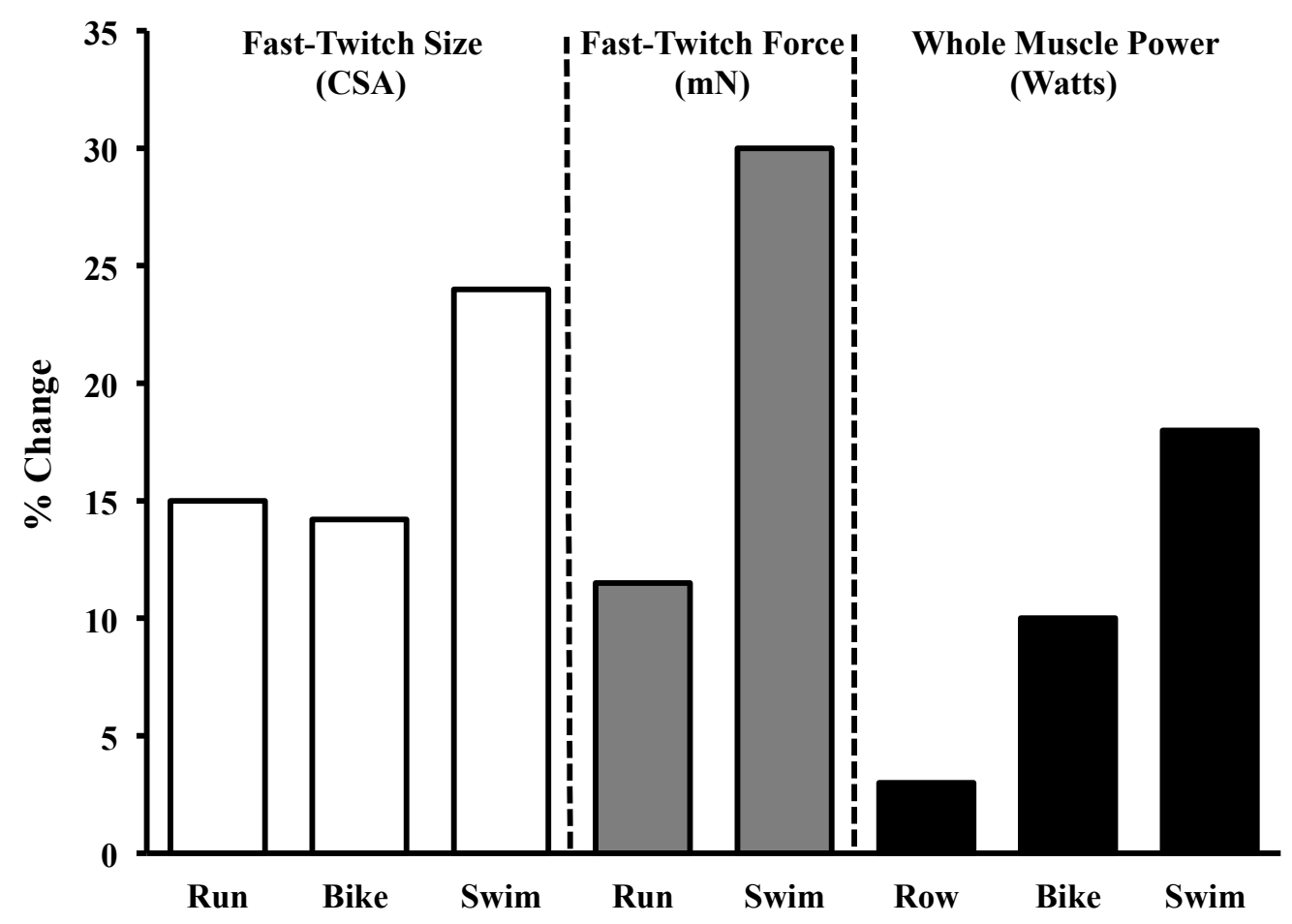

Figure 3. Skeletal muscle improvements from taper across different exercise modes and muscles. Data were derived from the following studies in order from left to right: Fast-Twitch Size-Luden et al. 2010 [5], Neary et al. 2003 [26], Trappe et al. 2000 [22]. Fast-Twitch Force-Luden et al. 2010 [5], Trappe et al. 2000 [22]. Whole Muscle Power-Steinacker et al. 2000 [21], Jeukendrup et al. 1992 [41], Costill et al. 1985 [4]. $\mathrm{CSA}=$ Cross Sectional Area; $\mathrm{mN}=$ Millinewtons. 


\section{How Tapering Improves Performance in Strength and Power Athletes}

In the early phases of resistance training, neuromuscular mechanisms largely contribute to strength increases independent from cellular mechanisms [44,45]. It follows that strength augmentation in the early phase of taper $(\leq 1$ week) after heavy resistance training could be attributable to a reversal of neuromuscular fatigue, specifically in highly-conditioned muscle [46]. Strength improvements could also be mediated by general recovery from wear and tear caused by intense resistance training. This is evidenced by reduced circulating markers of muscle damage with taper after progressive resistance training in team sport athletes [47]. Increased muscle strength generally equates to improved power production $[29,48]$ since power is the product of strength and speed. However, the mechanism of improved muscle function is not particularly well-documented in dedicated power athletes (e.g., competitive Olympic-style weightlifters). Regardless, total work, average peak power, repeated sprint ability, vertical jump height, and maximal power output in power-oriented athletes is observed with 10 days to three weeks of tapering $[18,19,49,50]$. These findings support the "rest-related augmentation" or "super-compensation" concept familiar to strength- and power-focused athletes who employ a long-term periodized training model that favors intensity over volume as competition approaches [51]. While additional mechanisms responsible for tapering's positive effect in strength, power, and team sport athletes remain to be elucidated, performance benefits are clear and tapering should be part of their training programs just as with endurance-type athletes.

\section{Summary and Perspectives}

The full complement of physiological effects from tapering are numerous and extend beyond the scope of this article (see Mujika et al. [52] and Pritchard et al. [17] for thorough reviews). However, the take-home points from the literature are: 1) fitness is not lost with reduced-volume training; 2) the profound effects of taper on whole muscle and fast-twitch fiber power are what appear to most greatly contribute to performance enhancement in endurance athletes; and 3) tapering is effective for improving performance in strength, power, and team sport athletes, but likely for different reasons than in endurance athletes. It should also be noted that psychological research on taper reveals that tapering improves mood state $[7,21,53]$ and decreases perception of effort $[54,55]$ in conjunction with improved performance. While more difficult to quantify, the psychological benefits that taper may afford prior to competition should not be understated. Nearly every well-controlled study to date on the topic of taper has shown some degree of performance enhancement so long as training volume is adequately reduced and intensity is maintained.

\section{Practical Applications}

The signals for adaptive processes occur during acute exercise bouts, but the actual adaptations take place during the proceeding rest periods. It follows that after a long period of chronic high-volume training that an extended period of relative rest and recovery is necessary to reap maximal performance benefits. Generally speaking, the problem with most athletes is not a lack of training rigor but demonstrating discipline and "pulling back" on training when necessary. This is evidenced by the recent findings that: 1) some elite and world-champion athletes do not adhere to the optimal tapering protocols 
outlined by the scientific literature and likely do not achieve true peak performance [56,57]; and 2) functional over-reaching, a common practice among recreational and elite athletes alike, may undercut the benefits of tapering [58]. Thus, tapering is adequately described by the adage "less is more" because maintained intensity with less volume yields significant performance benefits.

\section{Author Contributions}

Kevin A. Murach made substantial contributions to overall conception, drafting, and critically revising the manuscript. James R. Bagley made substantial contributions to drafting and critically revising the manuscript. Both authors approved of the final version to be published.

\section{Conflicts of Interest}

The authors declare no conflict of interest.

\section{References}

1. Spivey, J. The Ancient Olympics; Oxford University Press: Oxford, UK, 2004.

2. Bompa, T. Theory and Methodology of Training: The Key to Athletic Performance; Kendall/Hunt Publishing Company: Dubuque, IA, USA, 1983.

3. Matveev, L.P. Periodization of Sport Training; Fizkultura I Sport: Moskow, Russia, 1965.

4. Costill, D.; King, D.; Thomas, R.; Hagreaves, M. Effects of reduced training on muscular power in swimmers. Phys. Sport Med. 1985, 13, 94-101.

5. Luden, N.; Hayes, E.; Galpin, A.; Minchev, K.; Jemiolo, B.; Raue, U.; Trappe, T.A.; Harber, M.P.; Bowers, T.; Trappe, S. Myocellular basis for tapering in competitive distance runners. J. Appl. Physiol. 2010, 108, 1501-1509.

6. Murach, K.; Raue, U.; Wilkerson, B.; Minchev, K.; Jemiolo, B.; Bagley, J.; Luden, N.; Trappe, S. Single muscle fiber gene expression with run taper. PLoS ONE 2014, 9, doi:10.1371/journal.pone.0108547.

7. Berger, B.; Motl, R.; Butki, B.; Martin, D.; Wilkinson, J. Mood and cycling performance in response to three weeks of high-intensity, short-duration overtraining, and a two-week taper. Sport Psychol. 1999, 13, 444-457.

8. Neary, J.P.; Martin, T.P.; Reid, D.C.; Burnham, R.; Quinney, H.A. The effects of a reduced exercise duration taper programme on performance and muscle enzymes of endurance cyclists. Eur. J. Appl. Physiol. Occup. Physiol. 1992, 65, 30-36.

9. D'Acquisto, L. Changes in aerobic power and swimming economy as a result of reduced training volume. Biomechem. Med. Swim. 1992, 20, 201-205.

10. Shepley, B.; MacDougall, J.D.; Cipriano, N.; Sutton, J.R.; Tarnopolsky, M.A.; Coates, G. Physiological effects of tapering in highly trained athletes. J. Appl. Physiol. 1992, 72, 706-711.

11. Harber, M.P.; Gallagher, P.M.; Creer, A.R.; Minchev, K.M.; Trappe, S.W. Single muscle fiber contractile properties during a competitive season in male runners. Am. J. Physiol. Regul. Integr. Comp. Physiol. 2004, 287, R1124-R1131. 
12. Costill, D.L.; Flynn, M.G.; Kirwan, J.P.; Houmard, J.A.; Mitchell, J.B.; Thomas, R.; Park, S.H. Effects of repeated days of intensified training on muscle glycogen and swimming performance. Med. Sci. Sports Exerc. 1988, 20, 249-254.

13. Costill, D.L.; Thomas, R.; Robergs, R.A.; Pascoe, D.; Lambert, C.; Barr, S.; Fink, W.J. Adaptations to swimming training: Influence of training volume. Med. Sci. Sports Exerc. 1991, 23, 371-377.

14. Mujika, I.; Padilla, S. Scientific bases for precompetition tapering strategies. Med. Sci. Sports Exerc. 2003, 35, 1182-1187.

15. Bosquet, L.; Montpetit, J.; Arvisais, D.; Mujika, I. Effects of tapering on performance: A meta-analysis. Med. Sci. Sports Exerc. 2007, 39, 1358-1365.

16. Wilson, J.; Wilson, G. A practical approach to the taper. Str. Cond. J. 2008, 30, 10-17.

17. Pritchard, H.; Keogh, J.; Barnes, M.; McGuigan, M. Effects and mechanisms of tapering in maximizing muscular strength. Strength Cond. J. 2015, 37, 72-83.

18. Zaras, N.D.; Stasinaki, A.N.; Krase, A.A.; Methenitis, S.K.; Karampatsos, G.P.; Georgiadis, G.V.; Spengos, K.M.; Terzis, G.D. Effects of tapering with light vs. heavy loads on track and field throwing performance. J. Strength Cond. Res. 2014, 28, 3484-3495.

19. De Lacey, J.; Brughelli, M.; McGuigan, M.; Hansen, K.; Samozino, P.; Morin, J. The effects of tapering on power-force-velocity profiling and jump performance in professional rugby league players. J. Strength Cond. Res. 2014, 28, 3567-3570.

20. Cavanaugh, D.; Musch, K. Arm and leg power of elite swimmers increase after taper as measired by biokinetic variable resistance machines. J. Swim. Res. 1989, 5, 7-10.

21. Steinacker, J.M.; Lormes, W.; Kellmann, M.; Liu, Y.; Reissnecker, S.; Opitz-Gress, A.; Baller, B.; Gunther, K.; Petersen, K.G.; Kallus, K.W.; et al. Training of junior rowers before world championships. Effects on performance, mood state and selected hormonal and metabolic responses. J. Sports Med. Phys. Fit. 2000, 40, 327-335.

22. Trappe, S.; Costill, D.; Thomas, R. Effect of swim taper on whole muscle and single muscle fiber contractile properties. Med. Sci. Sports Exerc. 2000, 32, 48-56.

23. Houmard, J.A.; Scott, B.K.; Justice, C.L.; Chenier, T.C. The effects of taper on performance in distance runners. Med. Sci. Sports Exerc. 1994, 26, 624-631.

24. Neary, J.P.; Bhambhani, Y.N.; McKenzie, D.C. Effects of different stepwise reduction taper protocols on cycling performance. Can. J. Appl. Physiol. 2003, 28, 576-587.

25. Margaritis, I.; Palazzetti, S.; Rousseau, A.-S.; Richard, M.-J.; Favier, A. Antioxidant supplementation and tapering exercise improve exercise-induced antioxidant response. J. Am. Coll. Nutr. 2003, 22, 147-156.

26. Neary, J.P.; Martin, T.P.; Quinney, H.A. Effects of taper on endurance cycling capacity and single muscle fiber properties. Med. Sci. Sports Exerc. 2003, 35, 1875-1881.

27. Banister, E.W.; Carter, J.B.; Zarkadas, P.C. Training theory and taper: Validation in triathlon athletes. Eur. J. Appl. Physiol. Occup. Physiol. 1999, 79, 182-191.

28. Zarkadas, P.C.; Carter, J.B.; Banister, E.W. Modelling the effect of taper on performance, maximal oxygen uptake, and the anaerobic threshold in endurance triathletes. Adv. Exp. Med. Biol. 1995, 393, 179-186. 
29. Izquierdo, M.; Ibanez, J.; Gonzalez-Badillo, J.J.; Ratamess, N.A.; Kraemer, W.J.; Hakkinen, K.; Bonnabau, H.; Granados, C.; French, D.N.; Gorostiaga, E.M. Detraining and tapering effects on hormonal responses and strength performance. J Strength Cond. Res. 2007, 21, 768-775.

30. Mujika, I.; Padilla, S.; Pyne, D. Swimming performance changes during the final 3 weeks of training leading to the sydney 2000 olympic games. Int. J. Sports. Med. 2002, 23, 582-587.

31. Vandenberghe, K.; Hespel, P.; Vanden Eynde, B.; Lysens, R.; Richter, E.A. No effect of glycogen level on glycogen metabolism during high intensity exercise. Med. Sci. Sports Exerc. 1995, 27, 1278-1283.

32. Hargreaves, M.; Finn, J.P.; Withers, R.T.; Halbert, J.A.; Scroop, G.C.; Mackay, M.; Snow, R.J.; Carey, M.F. Effect of muscle glycogen availability on maximal exercise performance. Eur. J. Appl. Physiol. Occup. Physiol. 1997, 75, 188-192.

33. Snyder, A.C.; Kuipers, H.; Cheng, B.; Servais, R.; Fransen, E. Overtraining following intensified training with normal muscle glycogen. Med. Sci. Sports Exerc. 1995, 27, 1063-1070.

34. Rockwell, M.S.; Rankin, J.W.; Dixon, H. Effects of muscle glycogen on performance of repeated sprints and mechanisms of fatigue. Int. J. Sport Nutr. Exerc. Metab. 2003, 13, 1-14.

35. Balsom, P.D.; Gaitanos, G.C.; Soderlund, K.; Ekblom, B. High-intensity exercise and muscle glycogen availability in humans. Acta. Physiol. Scand. 1999, 165, 337-345.

36. Bergstrom, J.; Hermansen, L.; Hultman, E.; Saltin, B. Diet, muscle glycogen and physical performance. Acta. Physiol. Scand. 1967, 71, 140-150.

37. Sherman, W.M.; Costill, D.L.; Fink, W.J.; Miller, J.M. Effect of exercise-diet manipulation on muscle glycogen and its subsequent utilization during performance. Int. J. Sports. Med. 1981, 2, 114-118.

38. Johns, R.A.; Houmard, J.A.; Kobe, R.W.; Hortobagyi, T.; Bruno, N.J.; Wells, J.M.; Shinebarger, M.H. Effects of taper on swim power, stroke distance, and performance. Med. Sci. Sports. Exerc. 1992, 24, 1141-1146.

39. Van Handel, P.; Katz, A.; Troup, J.; Daniels, T.; Bradley, P. Oxygen consumption and blood lactic acid response to training and taper. Swim. Sci. 1988, 269-275.

40. Halson, S.L.; Bridge, M.W.; Meeusen, R.; Busschaert, B.; Gleeson, M.; Jones, D.A.; Jeukendrup, A.E. Time course of performance changes and fatigue markers during intensified training in trained cyclists. J. Appl. Physiol. 2002, 93, 947-956.

41. Jeukendrup, A.E.; Hesselink, M.K.; Snyder, A.C.; Kuipers, H.; Keizer, H.A. Physiological changes in male competitive cyclists after two weeks of intensified training. Int. J. Sports Med. 1992, 13, 534-541.

42. Papoti, M.; Martins, L.E.; Cunha, S.A.; Zagatto, A.M.; Gobatto, C.A. Effects of taper on swimming force and swimmer performance after an experimental ten-week training program. J. Strength Cond. Res. 2007, 21, 538-542.

43. Trinity, J.D.; Pahnke, M.D.; Reese, E.C.; Coyle, E.F. Maximal mechanical power during a taper in elite swimmers. Med. Sci. Sports Exerc. 2006, 38, 1643-1649.

44. Moritani, T.; de Vries, H.A. Neural factors versus hypertrophy in the time course of muscle strength gain. Am. J. Phys. Med. 1979, 58, 115-130.

45. Hakkinen, K.; Komi, P.V. Electromyographic changes during strength training and detraining. Med. Sci. Sports. Exerc. 1983, 15, 455-460. 
46. Hakkinen, K.; Kallinen, M.; Komi, P.V.; Kauhanen, H. Neuromuscular adaptations during short-term "normal" and reduced training periods in strength athletes. Electromyogr. Clin. Neurophysiol. 1991, 31, 35-42.

47. Coutts, A.; Reaburn, P.; Piva, T.J.; Murphy, A. Changes in selected biochemical, muscular strength, power, and endurance measures during deliberate overreaching and tapering in rugby league players. Int. J. Sports Med. 2007, 28, 116-124.

48. Chtourou, H.; Anis, C.; Tarak, D.; Mohamed, D.; Behm, D.G.; Karim, C.; Nizar, S. The effect of training at the same time of day and tapering period on the dirunal variation of short exercise performances. J. Strength Cond. Res. 2012, 26, 697-708.

49. Bishop, D.; Edge, J. The effects of a 10-day taper on repeated-sprint performance in females. J. Sci. Med. Sport 2005, 8, 200-209.

50. Eliakim, A.; Nemet, D.; Bar-Sela, S.; Higer, Y.; Falk, B. Changes in circulating igf-i and their correlation with self-assessment and fitness among elite athletes. Int. J. Sports Med. 2002, 23, 600603.

51. Weiss, L.W.; Wood, L.E.; Fry, A.C.; Kreider, R.B.; Relyea, G.E.; Bullen, D.B.; Grindstaff, P.D. Strength/power augmentation subsequent to short-term training abstinence. J. Strength Cond. Res. 2004, 18, 765-770.

52. Mujika, I.; Padilla, S.; Pyne, D.; Busso, T. Physiological changes associated with the pre-event taper in athletes. Sports Med. 2004, 34, 891-927.

53. Raglin, J.S.; Koceja, D.M.; Stager, J.M.; Harms, C.A. Mood, neuromuscular function, and performance during training in female swimmers. Med. Sci. Sports Exerc. 1996, 28, 372-377.

54. Flynn, M.G.; Pizza, F.X.; Boone, J.B., Jr.; Andres, F.F.; Michaud, T.A.; Rodriguez-Zayas, J.R. Indices of training stress during competitive running and swimming seasons. Int. J. Sports Med. 1994, 15, 21-26.

55. Martin, D.T.; Scifres, J.C.; Zimmerman, S.D.; Wilkinson, J.G. Effects of interval training and a taper on cycling performance and isokinetic leg strength. Int. J. Sports Med. 1994, 15, 485-491.

56. Spilsbury, K.L.; Fudge, B.W.; Ingham, S.A.; Faulkner, S.H.; Nimmo, M.A. Tapering strategies in elite british endurance runners. Eur. J. Sport. Sci. 2014, 15, 1-7.

57. Tonnesson, E.; Sylta, O.; Haugen, T.A.; Hem, E.; Svedsen, I.S.; Seiler, S. The road to gold: Training and peaking characteristics in the year prior to a gold medal endurance performance. PLOS ONE 2014, 9, doi:10.1371/journal.pone.0101796.

58. Aubry, A.; Hausswirth, C.; Louis, J.; Coutts, A.J.; LE Meur, Y. Functional overreaching: The key to peak performance during the taper? Med. Sci. Sports Exerc. 2014, 46, 1769-1777.

(C) 2015 by the authors; licensee MDPI, Basel, Switzerland. This article is an open access article distributed under the terms and conditions of the Creative Commons Attribution license (http://creativecommons.org/licenses/by/4.0/). 